\title{
Understanding and exploring employees' use of an enterprise social network within a large retail organization
}

\author{
Dammon Ghanizadeh \\ University of Hertfordshire \\ d.ghanizadeh2@herts.ac.uk
}

\author{
Prof. Jyoti Choudrie \\ University of Hertfordshire \\ j.choudrie@herts.ac.uk
}

\author{
Prof. David Sundaram \\ University of Auckland \\ d.sundaram@auckland.ac.nz
}

\begin{abstract}
This research aims to explore, understand and explain the use of an Enterprise Social Network within a large retail organisation. For this purpose, a qualitative approach of interpretivism and analytical technique of thematic analysis and open coding drawn from grounded theory were employed. The context of this study was a large retail organisation in the UK. The implications of this study for academia and industry are also included in this paper.
\end{abstract}

\section{Introduction}

The penetration of Information and Communication Technologies (ICTs) is growing at exponential rates, which is affecting societies, countries and organisations [1]. Due to the high penetration rates of ICTs, services enabled by these technologies are becoming more important within society, and much more prevalent [2]. One innovative form of ICT that is presently impacting both society as a whole and individual organisations is the Online Social Networks (OSNs), or more generally known as social media. The increasing penetration rates of OSNs have led to various digital transformations in many aspects of life, and the ways in which organisations and individuals communicate have changed significantly [3]. Over the last decade, many organisations have implemented OSNs to facilitate the exchange of knowledge between employees [4;5]. Research has shown that OSNs have the potential to contribute to knowledge exchange in the organisational context [6] by enabling professionals to maintain ongoing, high-quality relationships with influencers, media, customers and partners, regardless of where they are located [7]. Organisations have used OSNs in two ways that includes the development of Enterprise Social Media (ESM) [8;9]. Second, the use of using Enterprise Social Networks (ESNs) [9]. ESM is used as a tool for communication with external parties [9]. ESNs have improved organisational communication processes by creating visibility, persistence, editability, and association [10]. Successful information-seeking is a cost-effective process of identifying the knowledge of other employees, appreciating that knowledge, gaining easy access to other employees, and pursuing the information [11]. However, new ICTs are not accepted easily within organisations in many cases. One major barrier involves convincing employees to use them [12]. In many cases, individuals are not motivated to use ICTs for several reasons, including the structure of the organisation, the strategy that is used, the support mechanisms that are in place [13] and a lack of trust by employees [14]. Research into the use of ICTs has found that resistance arises due to the emergence of such challenges within organisations, which leads to a diverse range of working practices $[15 ; 16 ; 17 ; 18]$. The retail sector plays an important role in the UK economy and consistently contributes significantly to the gross value added [19]. Studies such as [20] indicate that OSNs can foster a higher level of information sharing within retail industry members. Considering the mentioned potential advantages of ESNs, successful implementation of ESNs can improve the process speed and efficiency in retail sector and thus the whole economy. A literature review and anecdotal evidence indicated that there are not any studies identifying and understanding the factors that affect the usage of ESNs within large retail sector organisations. The motivation for this paper is based on the fact that although ESNs are increasing in number within organisations, there are many different ways in which they are and are not being used and their application is still not understood. Finally, literature reviews suggested that studies of ESN use have not been researched extensively using a qualitative case study approach is rare; thereby motivating this study to consider this matter. In view of this, the aim of this study was formed as follows: To explore, understand and explain the use of an ESN within a large organisation. For the readers' benefit, the context of the organisation will be a retail sector organization in the United Kingdom (UK). To fulfil the aim of this study, the following research question was developed: How, what, when, where and why do employees use or avoid using an ESN within an organisation?

\section{Theoretical Background}


In this section, the gaps found in the research area of using ESNs are discussed.

\subsection{Resistance to using ESNs}

When examining ESN usage, one of the main concepts that prevents its use is resistance, which is used as the opposite of the notion of compliance $[21 ; 9 ;]$. Compliance represents acceptance of a technology. In the context of Information Systems, resistance is inevitable [9]. Although workforce resistance to the acceptance and usage of ICTs has largely been viewed as a negative behaviour, research has also shown that resistance can be also positive [21,9]. Both negative and positive resistance behaviours are indicated in users who are unable to follow the new process, and those affected by the functions of a system. This is defined as a workaround $[9 ; 21 ; 22 ; 23]$.

\subsection{Workaround}

A workaround is an action arising from resistance $[9 ; 21 ; 23 ; 24]$. [24] classified a workaround as a necessary activity or creative art, and viewed it in terms of behaviour, resistance, sources of future improvements, quick fixes, add-ons and shadow systems. Studies about IS and social networks classified workarounds into three types: hindrance, harmless and essential workarounds [21;9]. A hindrance workaround occurs when the system process is stopped or delayed. In this case, it is time-consuming and difficult to use a system, which leads to the user seeking a workaround to complete a task [25]. A harmless workaround does not affect the workflow or the accuracy of the data [26], while an essential workaround is essential to complete a task [23;25]. Wide range of literature about IS and social networks has studied factors affecting users' use of IS and OSNs and identified three areas of resistance that can lead to users' workaround. These three areas are system oriented [9;26;27;28], people oriented [9;26;29] and interaction oriented [26;28;30]. Moreover, literature shows there are some general external and internal elements that can impact users' resistance to IT, and employees' choices to apply workarounds in terms of using an ESN [21;9]. Although there is a wide literature about resistance and workarounds, there are very limited literature studying factors affecting workaround implementation among ESN users. Studies such as [9] have compared the usage of different social networks but they have considered limited external and internal pressures that lead to workaround implementation. The present study contributes to the existing literature by considering more external and internal pressures in order to determine what, when, where, why and how these factors encourage the use of workarounds. It also includes more organisational factors to explore the dynamics of workarounds within a large retail organisation. Although there is a wide body of literature that discusses the various factors affecting employees' resistance towards using ICTs; eg. prior experience, lack of need [31] and poorly designed systems [21], previous work has shown that this resistance may not be directed solely towards a particular system. Instead this could be resistance towards employment[21]. Workforce resistance can also originate from various factors, such as the culture and politics of the entire organisation $(13 ; 32 ; 33 ; 34]$.

\subsection{Organisational Culture}

Organisational culture is "the collective programming of the mind which distinguishes the members of one organisation from another" [35; $p 6]$. It includes "shared meanings - patterns of belief, symbols, rituals and myth that evolve across time and that function as social glue" [36;p344]. In an organisation with a supportive and innovative culture, employees are encouraged to be innovative, to learn new things, and to try new work processes or new technologies. However, in an organisation with an unsupportive culture, employees are reluctant to adapt, or may resist change[37]. The degree of adoption of innovation can therefore be regarded as an output of organisational culture with components such as norms, values and beliefs[38]. [39] defined three levels of organisational culture: artefacts (relates to the physical attributes of an organisation); espoused values (reflects the apparent culture of the organisation's stakeholders such as strategies, goals and philosophies); and basic underlying assumptions (the deepest level, and refers to the organisation's implicit hypothesis). Different studies used Schein's cultural levels to study how employees interact within the work environment. For example, [40] introduced a model of the determinants of organisational culture that can affect innovation within an organisation and believed that Schein's cultural levels can explain employees' interaction with an innovation within organisation. This study therefore aims to contribute to current research by providing organisations with a novel appreciation of the interdependencies between the organisational culture and the usage of an ESN.

\subsection{Trust}

Trust, defined as a strong belief in the capability of a thing to operate consistently, securely and dependably in a particular context [42]. In general, the literature indicates that with regard to knowledge sharing within organisations, trust may prompt some employees to use more traditional communication tools 
such as mailing files to colleagues in response to their questions, or giving information over the phone [43].Trust can be categorised into four types: ability (a set of skills, competencies and characteristics within a specific domain), integrity (an individual's perception that an exchange partner will adhere to a set of principles that are accepted by that individual), benevolence (the extent to which an exchange partner is believed to wish to do good towards the customer[9;44] and predictability (the extent to which the actions of the other partner can be predicted [45]. In ICT adoption literature, trust has been defined as a vital determinant [46]. At an organisational level, trust influences relationships, enabling cooperation[47]. Employees who do not trust an organisation or top management, may resist ICT initiatives; thereby, leading to resistance [48]. Following the development of virtual teams, the role of ESNSs in the internal knowledge sharing of organisations has become more significant [49]. Employees may resist using an ESN because of the lack of reliability or security[50], usefulness of the information, the organisational attitude towards employees' feedback and the transparency of its policies [51]. This research therefore contributes to current practice by informing policymakers about the challenges that might arise beyond adoption and during the actual use of the ESN. It also contributes to enriching the extant literature associated with the relationship between trust and the use of ESNs. The literature shows that although ESNs offer new possibilities, rules, and modes of communication [52], they may result in important changes in working practices and in greater flexibility and self-determination for staff [53].

\subsection{Working Practices}

Several IS and social networks studies have used an institutional approach to analyse the adoption and usage of ISs in organisations [9;31;54]. Since an ESN is also an IS, and since this study focuses on the ways in which a ESN is implemented and used within an organisation, an overview of institutional theory is needed in order to understand these systems [9;55]. Institutional theory refers to organisations as institutions, which implies that they have a distinct personality and monitoring is an important process. This involves the occurrence of specific forms, processes, strategies, outlooks and competences as they arise from patterns of organisational interaction and adaption $[31 ; 56]$. Thus, when technology is institutionalised, its acceptance and usage within the organisations are converted into routine activities, and users do not perform their day-to-day jobs without implementing the technology [50]. Technology acts as a necessary factor that integrates the sub-institutions within the organisation and shapes its system and legitimacy. Activities that are required for the development and use of a specific technology are affected by social, cultural, organisational, technical, and other institutional pressures. These pressures can originate from external sources such as competitors, customers and governments, or from legitimated norms, rules, and logics that are rooted in the organisation[57;58;59]. Organisations may react to these pressures by following technological instructions [57] or by adjusting their working practices to fit the technology [54]. This part of this research can contribute to current practice by informing policymakers of the challenges that may emerge after the adoption of an ESN. In other words, the results of this research can be used to identify the best approaches that can applied, while highlighting areas that particularly need to be considered. This section of this research also contributes to the literature by proposing an interrelationship between organisational culture, trust and working practices and their overall impact on ESN usage behaviour, from an institutional viewpoint.

\section{Proposed Research Approach}

Since this study is exploring how and why employees respond differently to the usage of adopted ESN, the designed research approach uses the epistemology of interpretivism. Also utilized is a single case study of a large retail organisation in England. For the data collection, semi-structured interviews, and reference to archival documents have been used to ensure triangulation [60]. The semi-structured interviews contained open-ended questions that will also be used as formative evaluation to help enhance the study's reliability [61]. This study will be conducted in three phases, with the findings of this study contributing to the third phase. The first phase was about the content and construct validity of the interview questions. This was assessed by a panel of 15 experts. The expert panel included diverse industries' practitioners and academics who will have knowledge of the thematic areas. The second phase of this study involved the pilot. The pilot participants with various demographics were selected by using snowball and purposive sampling methods. Overall, 12 participants were interviewed in the pilot phase. The data from this phase was analysed using thematic analysis and open coding drawn from grounded theory. As this is an inductive research study, the flexibility of thematic analysis can be helpful in generating themes; thus an inductive thematic approach was applied. For the third phase, the participants for this study will be determined using theoretical saturation; 
i.e. until there is a high level of duplication in the participants' responses and no new themes emerge [62].

\subsection{Research Site Selection}

This study was conducted in the retail sector, and Sellers (name substituted for anonymity purposes) was selected on the basis that it is a large retail organization in the UK. Sellers has over 100,000 personnel and is unique for ensuring that the workforce are also stakeholders by becoming partners in the business. The researcher contacted the IT team to find out whether the company had made any kind of formal statement regarding the adoption of new technologies. Since 2012, Sellers has announced in several different internal newsletters that the company was applying a new approach to trial new technologies. In one of these articles from 2013, an IT senior manager emphasised the importance of using new technologies in the retail sector, and stated that the new technologies entering the Sellers needed to pass three tests: (i) whether a new technology adds value to all channels for customers; (ii) whether it streamlines the organisation or its new business processes; and (iii) how the existing systems will be affected, and what kind of integration is necessary. To enhance internal communication among partners, Sellers began maintaining an active Google+ platform, and daily updates have been posted since 2012. However, in 2014, the company announced that it was moving towards using a Google app called Hangouts for internal communication. It was noted that it was sometimes difficult to contact partners, especially when they were visiting a site or on the shop floor; therefore, Hangouts use across Sellers was expected to improve flexibility and speed up delivery of customer updates. Hangouts was also selected due its open source feature and being associated with Google, a brand name that everyone is aware of. The ESN to be considered for this study is Hangouts. Each Sellers' partner has his/her own Partnership Google account, which can be used to login to Hangouts. Partners can also share and request knowledge or information through the Hangouts groups in which they participate based on departmental category and can receive responses and contributions from other partners.

\section{Data analysis}

Studies such as [9] found that organizational level can affect the level of ESN usage. Therefore, this study categorised the candidates into three groups, based on their position within Sellers: Lower, medium and higher level employees. These three groups were determined by considering the employees' salary range and job descriptions. The lower-level range included shop floor assistants and installers, who were front-line employees and mainly interacted with customers. They were normally responsible for selling only one specific product/service at a time, and were not responsible for take part in group planning and meetings. The mid-level group included the customer support team and planners, jobs that were at a higher grade than the lower-level employees, and these could be considered back office workers. They met with customers only occasionally or by booking appointments. Employees at this level took part in team planning and activities. The top-level group included departmental and senior managers, employees who managed teams across regions or nationally, and who therefore needed to be in contact with employees from different locations/cities. To conduct inductive thematic analysis, both semantic and latent coding were used to allow the researcher to explore, understand and explain the use of an ESN within a large organisation, and newly identified concepts were therefore allowed to emerge in the coding process and thematic analysis. During the analysis, and as an understanding of the gathered data was reached, codes that explained by the literature and showing the impact of organisational culture [40], trust [46] and working practices [9] related to ESN usage quickly emerged. Throughout the inductive research process, several more codes relating to issues such as the impact of the pandemic, the departmental category, centralisation policy, outsourcing, and seasonal events also appeared. During the interviews, respondents referred to the dimensions of organisational culture introduced by [40], which originated from Schein theory. These dimensions are strategy, structure, support mechanisms, behaviour that encourages innovation (in relation to ESNs) and communication. Respondents also referred to different types of trust, both in relation to the use of OSNs generally and the ESN specifically. This trust can originate from personal characteristics, the organisation, and the interaction between these two [46]. In addition, when analysing the impact of working practices on the employees' usage of the ESN, a set of codes applied by [54] and [9] also emerged. These codes reflect the existence of extra- and intra-organisational pressures on employees' day-to-day work activities and their usage of the ESN. Besides the codes related to organisational culture, trust and working practices, which could be explained by the literature, further codes emerged through the inductive analysis and the use of openended questions. The interviews took place during and after the first COVID-19 lockdown, and respondents referred to the impact of the pandemic on their use of technology in their daily activities and the use of the ESN in their intra-organisational contacts. Thus, the pandemic emerged as one of the unique themes in this study. The next code that appeared to be important in 
relation to ESN usage was the employees' departmental category. The results of the interviews showed that employees from lower organisational levels did not generally use the ESN, as they rarely collaborated with a team to complete their daily tasks. On the other hand, mid- and top-level employees used the ESN because they mainly worked as part of a team to provide services to customers. However, the findings indicated that the level of ESN usage was diverse within employees from different departments. The departmental category was therefore an important factor to be considered in terms of an understanding of ESN usage within the organisation. Furthermore, as confirmed by senior managers during the interviews, Sellers planned a restructuring in 2015 to deploy its resources more efficiently. As part of this restructuring plan, a centralisation policy was introduced whereby the main administration teams such as after-sales care, collaboration and installation were centralised. These teams were moved from the branches to a single central office. The policy encouraged the use of an ESN for communication between branches and central office employees. This centralisation policy therefore emerged as another theme impacting the use of an ESN within the organisation.In addition to the centralisation policy, Sellers outsourced some of its services (such as IT support and catering) as part of the restructuring plan. These outsourced teams no longer form part of the organisation, meaning that employees cannot use the ESN to contact them. Hence, outsourcing emerged as another theme influencing the level of ESN usage. Finally, the impact of seasonal events on ESN usage was highlighted by respondents during the interviews. Several candidates emphasised that during seasonal events (such as Easter, Black Friday and Christmas sales), they used the ESN more often, while in normal periods they might use other types of communication tools instead. Seasonal events therefore appeared to be one of the themes affecting the usage of the ESN.

\section{Findings and analysis}

As described in the previous section, the main themes that emerged as reasons for using or not using Hangouts were organisational culture, trust, working practices, the COVID-19 pandemic, the departmental category, centralisation policy, outsourcing and seasonal events, all of which are explained in the following sub-sections.

\subsection{Organisational culture}

For the analysis, the theme of organisational culture was examined by considering Schein's (1985) theory where the following dimensions were applied: Artefacts, Espoused values and basic underlying assumptions: In this case study, the workforce are part of an organisation that recognizes them as stakeholders with a monetary interest; thereby, labelling them as partners with the organisation's mission statement highlighting this aspect. This was associated with the artefacts part of organisational culture. This relationship also affected the use of Hangouts. Workers who had worked for the organisation for a longer duration were used to manual processes and resisted the use of the ICT. Their managers were allowed to overlook this resistance and continue to encourage those who wanted to use Hangouts to do so. Therefore, there was no strict policy, no punishment for not using Hangouts and led to a lower level of Hangout use. Further, in terms of artefacts and Hangouts, there were no posters, or brochures, or manuals to refer to in case of any difficulties. Instead, the organization relied on the workers to utilize the ESN and overcome any challenges using their own personal networks, rather than any provided by the organisation. The espoused values and basic underlying assumptions in the organisation were very loosely coupled in the organisation. The organization did not value anyone in the organisation based on the use of the ESN. Instead, there was an assumption made that if someone faced any difficulty, then there would be some personal place, or someone to seek advice and guidance from personally, but there was no support or strategy to offer ICT support. Due to centralization, costs cutting, departments reduced, or in some cases, eliminated ICT support, which further shows that the organisation's emphasis was on profitability and productivity rather than to support, or prioritize training and support for the application of a novel ESN, Hangouts. This was mentioned by older adults, in employment for many years with the organization and mostly, middle or lower level position holders. Younger participants (aged between 25 to 50 years) at both the middle and lower levels appeared to be more confident at using the technology and needed less support.

\subsection{Trust}

Trust is defined as a strong belief in the capability of a thing to operate consistently, securely, and dependably in a particular context[63]. For this study, the dimensions of trust are: Ability, Integrity, Benevolence, Predictability. Since Hangouts is an open source platform that is free of charge and provided by Google. Further, it was assumed that since Google is widely available, its associated products and services are also free of charge and used by individuals in their daily lives, so the issue of training, support and wider knowledge exchange would be overcome and the 
workers would trust that ESN. That is, as Google is freely available and everyone knows it, the assumption was made that everyone would be able to use the ESN. Further, due to the brand name of Google, there was an element of integrity, so individuals would not have to be convinced to accept the new technology. This also aligned with the predictable and benevolent aspect as it was predicted that a well-known, daily life ESN would be better accepted and used. This also showed the kindness (benevolence) of the senior level individuals. That is, if there were mandatory policies to use some new technology, even more resistance would have appeared. To ensure that everyone can use the technology, the decision was made to utilise a freely available ESN. However, there are also problems associated with this, particularly, the security and privacy risks.

\subsection{Working practices}

Working practices are defined as "the way we do things around here" [64, p:46]. For the analysis, the theme of working practices was examined by considering institutional theory. According to institutional theory, activities that are required for the development and use of a specific technology are affected by top-down (macro level) and bottom-up (micro level) pressures [9;54]. Most of the respondents from different age groups mentioned that they were aware of the existence of governmental policies on the use of OSNs and this affected their decisions on information sharing in Hangouts. Further, they confirmed that there was no approved policy-based system for Hangouts at Sellers; thus, they could decide where and when to use the ESN. Therefore, policy directives and policy-based system are the top-down pressures affecting the use of Hangouts at Sellers. Moreover, since Hangouts does not officially form part of the procedures for completing daily tasks; ie. There was no defined policy for its use. The organisation is very objective-oriented, and employees have high levels of flexibility when choosing the processese of work. Therefore, they have the power to decide whether they want to use the ESN. However, all of Sellers' employees depending on their role, were given a certain type of device such as an iPhone, iPad or laptop. Hangouts is pre-installed on all these devices, so that all employees can access it easily. Hangouts was a form of support for employees seeking information for their everyday work. Hence, Hangouts can be considered to be loosely coupled with procedure and policy and decoupled from the system. The use of Hangouts in daily work activities was affected by material constraints such as time constraints. Respondents mentioned that on busy days, they mainly replied to interpersonal messages, and did not have enough time to view all their Hangouts group conversations. Moreover, the analysis showed that the work ethos was affecting the daily use of Hangouts. Mid- and top-level employees who used Hangouts more, mentioned the app being very useful for providing a high level of service to their customers by facilitating a fast open communication within employees working in different locations. In addition, respondents referred to the quality of the information provided through Hangouts compared to other methods of communication. Some of the mid-level employees stated that because managers were in the Hangouts groups and monitored the conversations, employees provided information and responded in detail, giving accurate answers, because they wanted to demonstrate their capability and knowledge. However, monitoring appeared to be a constraint that affected older employees particularly those who had been with the company longer. These employees believed that managers found it easier to monitor them indirectly through Hangouts.

\subsection{Pandemic}

Since the pilot interviews took place during and after the first COVID-19 lockdown, the respondents referred to the impact of the pandemic on their work and their level of use of Hangouts. Some of the employees (mainly at the lower organisational levels) were furloughed during the lockdown. However, most of the mid- and top-level employees worked online during this period. These two groups mainly worked on unfinished projects, new online customer orders, and planning for reopening. Respondents who worked online during the lockdown reported that they used Hangouts more often during this period. They provided several different reasons for this, including changes in working hours, and unavailability of certain other tools such as face to face conversations. Moreover, some of the employees mentioned that during the pandemic, they tried using Hangouts and intended to continue using it after the lockdown.

\subsection{Departmental category}

The analysis showed that employees from lower organisational levels generally did not use the ESN, as they rarely needed to collaborate with teams to achieve their daily tasks. Comparatively, mid- and toplevel employees used the ESN because they were mainly working as part of a team to provide a service to customers. Therefore, it was concluded that position and organisational level has an impact on the level of Hangouts usage. However, the findings show that the ESN usage is even different between two same level 
employees working for different departments. Sellers provides services to customers through various departments. One of the factors determining the level of Hangouts use amongst these service providers was the level of teamwork needed to provide a service, which varied from department to department. For example, mid-level employees working in fitted kitchens, bathrooms and bedrooms uses the ESN more than midlevel employees working in fashion services and beauty services. However, all top-level employees in all departments showed that they use the ESN in daily basis. The organisational level and departmental category therefore determine how much teamwork is required to finish a task, and hence form one of the determinants of the usage of Hangouts at Sellers.

\subsection{Centralisation policy}

A senior manager confirmed that in 2015, Sellers planned an organisational restructuring to use its resources more efficiently. As part of this restructuring plan, a centralisation policy was applied to the main admin teams (such as after-sales care, collaboration, and installation) and these were moved from the branches to a single central office. This centralisation policy encouraged the use of Hangouts for communication between the branch staff and the central office employees.

\subsection{Seasonal events}

Finally, the impact of seasonal events on ESN usage was highlighted by respondents during the interviews. Several candidates reported that during seasonal events (such as Easter, Black Friday, and Christmas sales), they used the ESN more often, while at other times they would be likely to use other types of communication tools instead. Employees are busier during seasonal events, which implied that they needed to communicate rapidly. With the availability of Hangout on work provided devices, there was more of an incentive and motivation to use Hangouts. However, during quieter times of the year, they tended to use other types of communication.

\section{Discussion}

The findings of the pilot study revealed that when considering organisational culture, Schein's, organisational culture dimensions including artifacts, espoused values and basic underlying assumptions are loosely coupled with the use of ESN within organisation. In addition, all the dimensions of trust including Ability, Integrity, Benevolence, Predictability are associated with resistance by users, and particularly older employees and those with a lower level of education. Further, working practices were impacted by both extra- and intra-organisational pressures. The findings of the pilot study showed that extraorganisational pressures caused employees to resist using the ESN. In terms of intra-organisational pressures, the dimensions of material constraints, discretion to couple and work ethos all affected the level of ESN usage. Further codes emerged through the inductive analysis and the use of open-ended questions. An analysis of these themes shows that the COVID-19 pandemic, departmental category, centralisation policy and seasonal events all affected the ESN usage. Moreover, different communication tools were used by Sellers' employees at different organisational levels. As discussed previously, lower-level employees did not use Hangouts, as they did not need to take part in team meetings and planning. Hence, Hangouts cannot be seen as a communication tool of choice for these employees. Mid-level employees needed to take part in group meetings and planning; therefore needed to be in contact with each other in order to complete their tasks. This group of employees reported that their first choices of contact method for one-to-one and group communication were WhatsApp and Hangouts. Several employees in this group stated that if they wanted to contact close colleagues, they used WhatsApp rather than Hangouts, since they were aware that Hangouts was a more formal way of communicating. Various themes including organisational culture, trust, working practices, the COVID-19 pandemic and seasonal events all impacted the choice between WhatsApp and Hangouts. In the absence of these two apps, this group of employees would communicate face-to-face, over the phone or through email. Top-level employees used Hangouts as their first choice of contact for daily conversations, and email to send important documents. This group of employees implemented workaround only when Hangouts was not accessible, for example if the person that they wanted to contact did not have access to Hangouts. The dimensions of organisational culture that resulted in employee resistance are Schein's, organisational culture dimensions including artifacts, espoused values, and basic underlying assumptions. It was noted above that the strategy and structure of Sellers is based on a partnership model, and are therefore objective-oriented, with less emphasis on the process of doing a task. Therefore, the artifacts dimension affected employees when facing harmless workarounds, since the results of their tasks were not affected by the implemented workarounds. Further, the espoused values and basic underlying assumptions dimensions of the organisational culture affected ESN use due to the non-existence of posters, brochures, manuals, or 
training at Sellers. Older employees and those with less experience of using different types of OSNs found using the ESN difficult, and were more likely to implement workarounds because they could not use the system properly; hence, espoused values and basic underlying assumptions dimensions of organisational culture led the employees to the use of hindrance workarounds. The dimensions of trust were all related to resistance behaviour, because users did not trust the system, their colleagues and/or the organisation. These employees preferred to use alternative tools to communicate with their colleagues. However, this workaround did not impact the quality of their work, and can also be categorised as a harmless workaround. An examination of working practices and extra- and intra-organisational pressures showed that both types of constraints prevented employees from using the system and promoted the use of workarounds. The existence of a policy directive, an extra-organisational pressure, caused a harmless workaround to be implemented by employees, as they found these rules to be insufficient to protect their information. Thus, this dimension is also interlinked with the different dimensions of trust. The second element of extra-organisational pressure is the use of policy-based systems. No policy was developed to specify employees should use Hangouts in their working practice; thus, employees could implement a workaround and complete their tasks without using the ESN. This dimension also led to a harmless workaround. An analysis of the intra-organisational elements such as material constraints, work ethos and discretion to decouple showed that the use of Hangouts helped Sellers' employees to provide a high quality of service to their customers. This meant that a work ethos encouraged the use of Hangouts. However, material constraints such as time led to the application of a workaround, which can be categorised as a hindrance workaround. Consideration of the discretion to decouple element indicated that the ESN was loosely coupled with the policies and decoupled from the system, and this enabled employees to apply a harmless workaround.

Thus, by analysing the themes of this study the impact of the COVID-19 pandemic, departmental category, centralisation and seasonal events all encouraged employees to use the ESN rather than to implement a workaround.

\section{Implications of this Research}

This research study has theoretical and practical implications. For academia, this research contributes to explanation of interrelationship between resistance, workaround, organisational culture, trust and working practices and their overall impact on the ESN usage behaviour, from an institutional standpoint, which is novel for the ESN arena. The proposed explanation also contributes to form theories of ESN design and action. For industry, the findings could enable employees and employers to use ESN as a cost-effective way of identifying the knowledge of other employees, appreciating that knowledge, contacting employees easily, and pursuing information. Thus, they will be able to improve the organisational communication processes by creating visibility, persistence, editability and association. A further contribution to practice is that these results can inform policymakers on the challenges that might arise beyond the adoption and during the actual use of an ESN in a large retail organisation. In other words, the results of this research can identify the best approach that should be applied, while highlighting certain areas that need to be considered.

\section{Conclusions}

This paper aims to explore, understand and explain the use of an ESN within a large organization. By applying interpretivism along with thematic analysis and open coding drawn from grounded theory it was found that when considering organisational culture, the dimensions of artifacts, espoused values and basic underlying assumptions are loosely coupled with the use of ESN within the organization. This resulted in the hindrance workaround. In addition, all the dimensions of trust including Ability, Integrity, Benevolence, Predictability (particularly within older employees and those with a lower level of education), along with working practices (impacted by both extra- and intraorganisational pressures) led employees to implement a harmless workaround. Further codes emerged through the inductive analysis and the use of open-ended questions. An analysis of these themes showed that the COVID-19 pandemic, departmental category, centralisation policy and seasonal events all encouraged the use of ESN. The primary limitation of this research is that it is contextualised within a single retail organization. This implies that generalisations in the form of an overall picture of the retail sector cannot be provided. However, since Sellers is a large organisation with numerous departments, and has many branches located nationally, this research may indeed capture the critical points regarding the use of ESNs in retail organisations. In future, this research could be extended by considering several international retail organisations.

\section{References}

[1] J. Choudrie, E.D. Zamani, and A. Al-Bulushi, "Are online social networks leading to a "better world in the Omani public sector? A qualitative study". In International Conference on the Social Implications of Computers in 
Developing Countries Springer, Cham, 2017, pp. 669680.

[2] M. Barrett, E. Davidson, J. Prabhu, and S.L. Vargo, "Service innovation in the digital age", MIS quarterly, 2015, 39(1), pp.135-154.

[3] J. Choudrie, P. Olla, and B. Bygstad, "The diffusion, impacts, adoption and usage of ICTs upon society", Journal of Information Technology Research, 2010, 3(1).

[4] J. Bughin, and M. Chui, "Evolution of the networked enterprise: McKinsey Global Survey results". McKinsey Quarterly, 2013, 29, 34-41.

[5] S. Pfisterer, A. Streim, and K. Hampe, Arbeit 3.0. Arbeiten in der digitalen Welt. Berlin: BITKOM, 2013.

[6] J. Moskaliuk, J. Kimmerle, and U. Cress "Wiki-supported learning and knowledge building: Effects of incongruity between knowledge and information", Journal of Computer Assisted Learning, 2009, 25(6), 549-561.

[7] M. Komodromos, "A STUDY OF PR PRACTITIONERS'USE OF SOCIAL MEDIA TOOLS IN CYPRUS", Journal of Developmental Entrepreneurship, 2014, 19(02), p.1450011.

[8] M.J. Piskorski, "Social strategies that work", Harvard business review, 2011, 89(11), pp.116-22.

[9] J. Choudrie and E.D. Zamani "Understanding individual user resistance and workarounds of enterprise social networks: The case of Service Ltd", Journal of Information Technology, 2016, 31(2), 130-151.

[10] P.M. Leonardi, and J.W. Treem, "Knowledge management technology as a stage for strategic selfpresentation: Implications for knowledge sharing in organizations", Information and Organization, 2012 22(1), pp.37-59.

[11] S.L. Jarvenpaa, and A. Majchrzak, "Knowledge collaboration among professionals protecting national security: Role of transactive memories in ego-centered knowledge networks", Organization Science, 2008 19(2), pp.260-276.

[12] J. Preece, and B. Shneiderman, "The reader-to-leader framework: Motivating technology-mediated social participation", AIS Transactions on Human-Computer Interaction, 2009, 1(1), 5.

[13] E.C. Martins and F. Terblanche, "Building organisational culture that stimulates creativity and innovation", European Journal of Innovation Management, 2003, 6(1), 64-74.

[14] J. Choudrie, C.O. Obuekwe, B. McKenna, and S. Richter, "Understanding and conceptualising the adoption, use and diffusion of mobile banking in older adults: A research agenda and conceptual framework", Journal of Business Research, 2017.

[15] C. Matschke, J. Moskaliuk, F. Bokhorst, T. Schümmer, and U. Cress "Motivational factors of information exchange in social information spaces", Computers in Human Behavior, 2014, 36, 549-558.

[16] H. Pirkkalainen, and J.M. Pawlowski, "Global social knowledge management-Understanding barriers for global workers utilizing social software", Computers in Human Behavior, 2014, 30, 637-647.

[17] A.A. Armenakis and S.G. Harris, "Reflections: Our journey in organizational change research and practice", Journal of change management, 2009, 9(2), pp.127-142.
[18] D. Özdemir-Güngör, and H. Camgöz-Akdağ, "Examining the effects of technology anxiety and resistance to change on the acceptance of breast tumor registry system: Evidence from Turkey", Technology in Society, 2018, 54, pp.66-73.

[19] D. Clark, 2021. Gross value added of the wholesale and retail trade, including repair of motor vehicles sector in the United Kingdom from 1990 to 2021. Available at: https:/www.statista.com/statistics/760100/wholesaleand-retail-trade-sector-gross-value-added-in-the-uk/ (Accessed 12 Sep 2021).

[20] S.F., Wamba, L.A. Lefebvre, and E. Lefebvre, 2006, August. Enabling intelligent B-to-B eCommerce supply chain management using RFID and the EPC network: a case study in the retail industry. In Proceedings of the 8th international conference on Electronic commerce: The new e-commerce: innovations for conquering current barriers, obstacles and limitations to conducting successful business on the internet (pp. 281-288).

[21] E.H. Ferneley and P. Sobreperez, "Resist, comply or workaround? An examination of different facets of user engagement with information systems", European Journal of Information Systems, 2006, 15(4), 345-356.

[22] L.A. Petrides, S.I. McClelland and T.R. Nodine, "Costs and Benefits of the Workaround: Incentive, Solution or Costly Alternative", International Journal of Educational Management, 2004, 18(2), 100-108.

[23] I.M. Kobayashami, S.R. Fussell, Y. Xiao and F.J. Seagull "Work Coordination, workflow and Workarounds in a

medical context, in CHI '05" Extended Abstracts on Human Factors in Computing Systems, 2005, 1561-1564.

[24] S. Alter, "Theory of Workarounds" Communications of the Association for Information Systems, 2014, 34, 10411066.

[25] G. Lankshear, P. Cook, D. Mason, S. Coates, and G. Button, "Call centre employees' responses to electronic monitoring: Some research findings", Work, Employment and Society, 2001, 15(3), pp.595-605.

[26] L. Lapointe, and S. Rivard, 2005. A multilevel model of resistance to information technology implementation. MIS quarterly, pp.461-491.

[27] M. Ali, L. Zhou, L. Miller, and P., Ieromonachou, 2016. User resistance in IT: A literature review. International Journal of Information Management, 36(1), pp.35-43.

[28] T. Klaus, and J.E., Blanton, 2010. User resistance determinants and the psychological contract in enterprise system implementations. European Journal of Information Systems, 19(6), pp.625-636.

[29] T.H. Tambunan, (2011) 'Development of small and medium enterprises in a developing country', Journal of Enterprising Communities: People and Places in the Global Economy, Vol. 5, No. 1, pp.68-82, DOI: 10.1108/17506201111119626.

[30] R. Meissonier, E. Houzé, and V. Bessière, 2013. Crosscultural frictions in information system management: Research perspectives on ERP implementation misfits in Thailand. International Business Research, 6(2), p.150.

[31] S. Laumer and A. Eckhardt, "Why do people reject technologies: a review of user resistance theories", Information systems theory, 2012, pp.63-86. 
[32] M.L. Markus, "Power, politics, and MIS implementation", Communications of the ACM, 1983, 26(6), pp.430-444.

[33] S. Ogbeibu, A. Senadjki, and J. Gaskin "The moderating effect of benevolence on the impact of organisational culture on employee creativity", Journal of Business Research, 2018, 90, pp.334-346.

[34] J. Choudrie and C. Castro Rodriguez, "Technostress: Exploring and understanding its duality through the experiences of individuals working in organizations", 2020.

[35] G. Hofstede, M. and Minkov, "Long-versus short-term orientation: new perspectives". Asia Pacific business review, 2010, 16(4), pp.493-504.

[36] L. Smircich, "Concepts of culture and organizational analysis", Administrative science quarterly, 1983, pp.339-358.

[37] F. Wolf and L. Brennan, "Framing the impact of organisational culture on innovation", In 17th Annual Irish Academy of Management, Limerick, 2014.

[38] M. Drent and M. Meelissen, "Which factors obstruct or stimulate teacher educators to use ICT innovatively?", Computers \& Education, 2008, 51(1), pp.187-199.

[39] E.H. Schein, "Defining organizational culture", Classics of organization theory, 1985, 3(1), pp.490-502.

[40] E.C. Martins and F. Terblanche, "Building organisational culture that stimulates creativity and innovation", European Journal of Innovation Management, 2003, 6(1), 64-74.

[41] A. Cantwell, L. Aiman-Smith, and T. Mullen, Dimensions of innovation culture: Developing a measure. In Society of Industrial Organizational Psychologists Meeting, Bildiri, New York, ABD, Nisan, 2007.

[42] T. Grandison and M. Sloman, "A survey of trust in internet applications", IEEE Communications Surveys \& Tutorials, 2000, 3(4), pp.2-16.

[43] A. Ardichvili, V. Page, and T. Wentling, "Motivation and barriers to participation in virtual knowledge sharing communities of practice", Journal of Knowledge Management, 2003, 7(1), 64-77.

[44] J. Choudrie, C.O. Junior, B. McKenna, and S. Richter, "Understanding and conceptualising the adoption, use and diffusion of mobile banking in older adults: A research agenda and conceptual framework", Journal of Business Research, 2018, 88, pp.449-465.

[45] M. Salehan, D.J. Kim, and C. Koo, "A study of the effect of social trust, trust in social networking services, and sharing attitude, on two dimensions of personal information sharing behavior", Journal of Supercomputing, 2018, 74(8), 3596-3619.

[46] F. Li, D. Piénkowski, A. van Moorsel, and C. Smith, "A holistic framework for trust in online transactions", International Journal of Management Reviews, 2012, 14(1), 85-103.

[47] S. Van den Heuvel, R. Schalk, and M.A. van Assen, "Does a well-informed employee have a more positive attitude toward change? The mediating role of psychological contract fulfillment, trust, and perceived need for change", The Journal of Applied Behavioral Science, 2015, 51(3), pp.401-422.
[48] R.K. Smollan, "Trust in change managers: the role of affect", Journal of Organizational Change Management, 2013, 26(4), pp.725-747.

[49] P.M. Leonardi and J.W. Treem, "Knowledge management technology as a stage for strategic selfpresentation: Implications for knowledge sharing in organizations", Information and Organization, 2012, 22(1), pp.37-59.

[50] P. Ratnasingam, P.A. and Pavlou, "Technology trust in internet-based interorganizational electronic commerce", Journal of Electronic Commerce in Organizations (JECO), 2003, 1(1), pp.17-41.

[51] V. Shankar, G.L. Urban, and F. Sultan, "Online trust: a stakeholder perspective, concepts, implications, and future directions", The Journal of strategic information systems, 2002, 11(3-4), pp.325-344.

[52] G. Ulmer, and J. Pallud, "Understanding usages and affordances of enterprise social networks: a sociomaterial perspective", 2014.

[53] A. Richter, C. Hetmank, J. Klier, M. Klier, and M. Müller, "Enterprise social networks from a manager's perspective", Hawaii International Conference on System Sciences (HICSS), 2016, January, pp. 42424251.

[54] B. Azad and N. King, "Institutionalized computer workaround practices in a Mediterranean country: an examination of two organizations", European Journal of Information Systems, 2012, 21(4), pp.358-372.

[55] J.C. Lammers, M.A. and Garcia, "Institutional theory approaches", The international encyclopedia of organizational communication, 2017, pp.1-10.

[56] P. Selznick, Law and the Structures of Social Action, 1957.

[57] A. Pishdad, A. Haider, and A. Koronios, "Technology and organizational evolution: An institutionalisation perspective", Journal of Innovation and Business Best Practices, 2012, 1.

[58] A. Genus and M. Iskandarova, "Transforming the energy system? Technology and organisational legitimacy and the institutionalisation of community renewable energy", Renewable and Sustainable Energy Reviews, 2020, 125, 109795.

[59] S.R. Jansma, J.F. Gosselt, K. Kuipers, and M.D. De Jong, "Technology legitimation in the public discourse: Applying the pillars of legitimacy on GM food", Technology Analysis \& Strategic Management, 2020, 32(2), 195-207.

[60] Y.S. Lincoln and E.G. Guba, "Establishing trustworthiness", Naturalistic inquiry, 1985, 289(331), pp.289-327.

[61] M.N. Saunders, Research methods for business students, 5th ed. India: Pearson Education, 2011.

[62] R.K. Yin, Case study research: Design and methods (3rd ed.). Thousand Oaks, CA: Sage, 2003.

[63] T. Grandison and M. Sloman, "A survey of trust in internet applications", IEEE Communications Surveys \& Tutorials, 2000, 3(4), pp.2-16.

[64] J. Schwartz, P. Gaito, and D. Lennick, "That's the way we (used to) do things around here", Strategy+ business, 2011, 62, pp.45-53. 